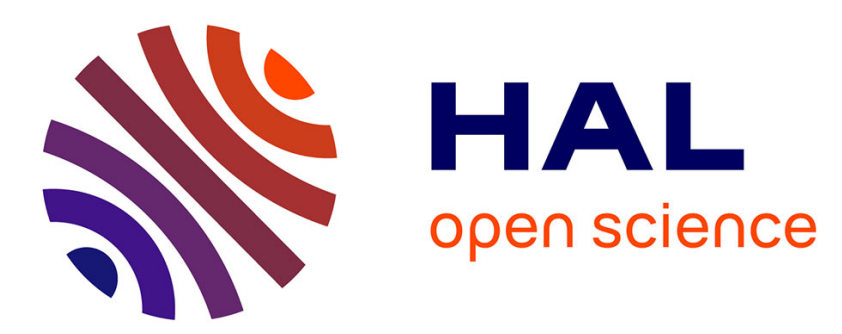

\title{
Preparation and properties of gold-infiltrated polystyrene photonic crystals
}

\author{
A.Z. Khokhar, F. Rahman, N.P. Johnson
}

\section{To cite this version:}

A.Z. Khokhar, F. Rahman, N.P. Johnson. Preparation and properties of gold-infiltrated polystyrene photonic crystals. Journal of Physics and Chemistry of Solids, 2011, 72 (3), pp.185. 10.1016/j.jpcs.2010.12.010 . hal-00720587

\section{HAL Id: hal-00720587 \\ https://hal.science/hal-00720587}

Submitted on 25 Jul 2012

HAL is a multi-disciplinary open access archive for the deposit and dissemination of scientific research documents, whether they are published or not. The documents may come from teaching and research institutions in France or abroad, or from public or private research centers.
L'archive ouverte pluridisciplinaire HAL, est destinée au dépôt et à la diffusion de documents scientifiques de niveau recherche, publiés ou non, émanant des établissements d'enseignement et de recherche français ou étrangers, des laboratoires publics ou privés. 


\section{Author's Accepted Manuscript}

Preparation and properties of gold-infiltrated polystyrene photonic crystals

A.Z. Khokhar, F. Rahman, N.P. Johnson

PII:

S0022-3697(10)00435-X

DOI:

Reference:

doi:10.1016/j.jpcs.2010.12.010

PCS 6382

To appear in:

Journal of Physics and

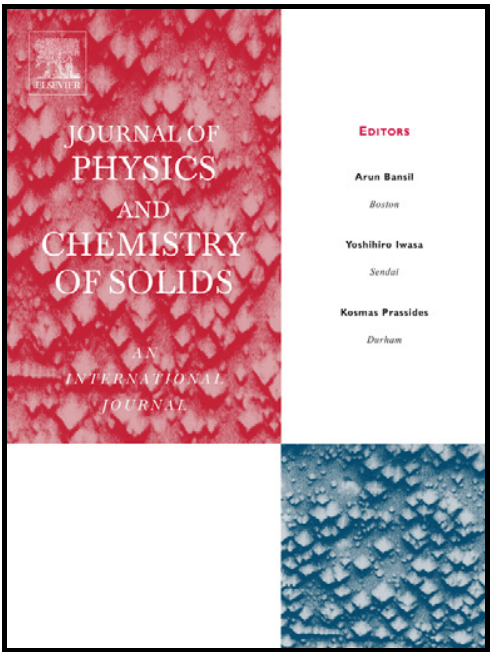

www.elsevier.com/locate/jpcs Chemistry of Solids

Received date: $\quad 8$ September 2010

Revised date: $\quad 12$ November 2010

Accepted date: 18 December 2010

Cite this article as: A.Z. Khokhar, F. Rahman and N.P. Johnson, Preparation and properties of gold-infiltrated polystyrene photonic crystals, Journal of Physics and Chemistry of Solids, doi:10.1016/j.jpcs.2010.12.010

This is a PDF file of an unedited manuscript that has been accepted for publication. As a service to our customers we are providing this early version of the manuscript. The manuscript will undergo copyediting, typesetting, and review of the resulting galley proof before it is published in its final citable form. Please note that during the production process errors may be discovered which could affect the content, and all legal disclaimers that apply to the journal pertain. 


\title{
Preparation and Properties of Gold-infiltrated Polystyrene Photonic Crystals
}

\author{
A. Z. Khokhar, F. Rahman and N. P. Johnson
}

Department of Electronics and Electrical Engineering

Optoelectronics Group

University of Glasgow

Rankine Building, Oakfield Avenue

Glasgow G12 8LT, United Kingdom

\section{ABSTRACT}

Artificial opals are an important class of photonic crystals that can be used for a number of different applications. Here we describe a simple process for doping the voids of polystyrene-based three-dimensional photonic crystals with metal nanoparticles. Our demonstration made use of nano-gold colloids but similar techniques can be used for incorporating nano-particles of other metals inside the interstices of self-assembled opals. A particularly attractive feature of our technique is that it allows thick opal films to be infiltrated easily with capillary forces transporting the active dopant inside the microporous material. The infiltration technique is described followed by a description of scanning electron microscopy performed on infiltrated samples. Gold nano-pillars with diameters of $35 \mathrm{~nm}$ have been observed between the domains and also on (111) plane. Results of optical reflection experiments carried out on infiltrated opals are described next which show the presence of surface plasmon resonance bands. 
Corresponding Author: Faiz Rahman

Telephone Number: +441413302091

Fax Number: +44 1413304067

E-mail Address: f.rahman@elec.gla.ac.uk

Keywords: A. microporous materials; A. optical materials; A. thin films; C. electron microscopy; D. optical properties

1. Introduction

Photonic crystals (PhCs) have attracted a lot of attention over the past two decades as their remarkable properties have been investigated both theoretically and experimentally. These materials show optical behaviour that is strongly reminiscent of electron waves in crystalline solids. Depending on their structural details, PhCs display optical band-gaps such that radiation within certain wavelength bands is unable to propagate through them. This kind of wavelengthselective transmission can be made use of in optical devices for generating, detecting and processing light. PhCs can be made in a number of different ways. Both thin films and bulk material can be fabricated through physical or chemical routes. Furthermore, some variants lend themselves to self-assembly whereas others are prepared using lithographic techniques. Self-assembled PhCs are generally three-dimensional structures whereas lithographically-patterned $\mathrm{PhC}$ are two-dimensional. The type of $\mathrm{PhC}$ made and its fabrication technology are 
dictated by the particular application the material is intended for. Many potential uses of PhCs require a thin film of the material on a transparent substrate. In this case, self-assembly of silica or polystyrene spheres can be used to form a uniform layer of stacked, close-packed spheres that exhibit characteristics of threedimensional PhCs. One can go a step further and dope the $\mathrm{PhC}$ by inserting desired dopants into the interstices of this structure. Techniques for carrying out this process have been described previously but here we report a particularly straightforward and flexible approach to infiltrate polystyrene $\mathrm{PhCs}$, also called polystyrene opals, with nano-gold colloids. Opals infiltrated with nano-gold colloids shows the superposition of $\mathrm{PhC}$ lattice diffraction with the surface plasmon resonance of gold particles.

In recent years metallo-dielectric PhCs working in the visible region have attracted considerable interest from both the science and engineering points of view. The main challenge is arguably to realise left handed materials, i.e. specific forms of meta-materials, on the basis of metallo-dielectric crystals [1,2]. Metallodielectric PhCs have already been shown to be useful for several potential applications in the microwave and far-infrared regions, where typical metals such as gold, silver and aluminium act as almost perfect reflectors $[3,4]$ Synthetic opal [5] fabricated by using a self-assembly approach, i.e. capillary growth of crystals of polystyrene [6] or silica [7] spheres, is one of the more interesting 3-D PhCs and can act as a template for the fabrication of metallo-dielectric 3-D crystals. In the literature, two principal properties of metallo-dielectric $\mathrm{PhCs}$ have been emphasised. These are the creation of a complete photonic band gap (CPBG) and the fabrication of macroporous metallic films. W.Y. Zhang et al [8], A. Moroz [9] 
and I. El-Kady [10] have shown both theoretically and experimentally that a CPBG can be achieved in the microwave region as well as in the visible region, if the spheres are coated with a thin layer of metal or if solid metal spheres are used. It was shown that the metal used could be gold, silver, aluminium or copper. In another work, P.N. Bartlett et al [11] demonstrated macroporous metallic films made of gold and platinum. These films were obtained by depositing the metal in the voids of an opal film by using electrochemical deposition followed by removal of the spheres. W. Li et al [12] have also demonstrated the infiltration of gold into the voids of opal made of $250 \mathrm{~nm}$ diameter silica spheres - by using electroplating techniques. With this technique, they infiltrated $1-3 \mu \mathrm{m}$ thick opal films i.e. up to $\sim 20$ layers of stacked spheres.

In the work reported here, a simple and inexpensive technique for the infiltration of nano-gold colloids into the voids of an opal film made of polystyrene spheres is described. Infiltration was achieved by using capillary forces. Polystyrene spheres, $230 \mathrm{~nm}$ in diameter were used to fabricate $25 \mu \mathrm{m}$ thick opal films. The high level of infiltration was observed using an SEM and the optical reflectance properties were measured. A red shift in the stop-band of the synthetic opal was observed due to the increase in the effective refractive index of the $\mathrm{PhC}$ material. It should be mentioned here that a similar technique for the preparation of three-dimensional macroporous titania (TiO2) films has also been developed [13]. In the rest of this paper we describe our infiltration techniques, structural characteristics of infiltrated opals and their optical properties.

2. Nano-gold colloid infiltration technique 
This work made use of polystyrene-based $\mathrm{PhCs}$ which were fabricated on glass substrates using capillary growth of $230 \mathrm{~nm}$ diameter polystyrene spheres [14]. 5 nm diameter mono-dispersed nano-gold colloid (with particle diameters in the range of 3.5 to $6.5 \mathrm{~nm}$ ) was obtained in the form of $\mathrm{HAuCl}_{4}$ solution (Chloroauric Acid) from Sigma-Aldrich. This inorganic acid consists of the square planar $\left[\mathrm{AuCl}_{4}\right]^{-}$ion and the proton is associated with water. The solution obtained from Sigma-Aldrich contained approximately $0.01 \% \mathrm{HAuCl}_{4}$ suspended in $0.01 \%$ tannic acid with $0.04 \%$ trisodium citrate - and $0.26 \mathrm{mM}$ of potassium carbonate. The solution was infiltrated into the voids of the opal by using capillary forces. The synthetic opal was blown with nitrogen gas to remove any fragile domains that were not well attached to the substrate before infiltration. The synthetic opal was then placed in a small vial containing $2-3 \mathrm{ml}$ of $\mathrm{HAuCl}_{4}$ solution, at an angle of $65^{\circ}$. A blank glass substrate of the same size was placed directly on top (i.e. (111) plane) of the synthetic opal, loosely touching the spheres. This arrangement gives a cell-like structure with a thin opal film sandwiched between the two glass substrates. The colour of the thin film changed within a few minutes due to the infiltration of Au into the voids of the opal. The infiltration was initially driven by capillary forces between the two glass slides as the colloid was taken up and later by capillary forces that existed between the polystyrene spheres. For slow evaporation of the solution, the vial was loosely capped and kept in a temperaturecontrolled environment. The temperature was set at $23{ }^{\circ} \mathrm{C}$ and the relative humidity was varied from $25 \%$ to $30 \%$. After two weeks of exposure in this environment, the sample was completely dry. The top glass was removed carefully and the sample was observed under optical and scanning electron microscopes 
(SEM). It was found that good infiltration could be obtained when the top glass substrate was placed on the (111) plane of the synthetic opal, with a para-film spacer.

Both optical and scanning electron microscopy was used to study gold infiltrated-PhCs. A Hitachi model S-4700 SEM was used for this purpose. Figure 1 shows an optical micrograph of a thin polystyrene opal film, before (a) and after (b) infiltration of Au nano-particles. The colour of the opal thin film, as observed in reflection, changed from yellowish-green to red by the infiltration process. This change in colour was due to both an increase in the effective refractive index of the composite film and the intrinsic colour of nano-gold colloid itself. Figure 2 shows SEM cross-sectional images of our $\mathrm{PhC}$ films before (top) and after (bottom) infiltration of $\mathrm{Au}$ nano-particles. The curvature apparent in the bottom panel of figure 2 is not a feature of the film but arises as some domains curl up under pressure of nitrogen gas stream used to remove loosely adhering domains. Cross-sections of the domains were also observed in the SEM, as shown in Figure 3. The formation of gold nano-pillars were observed in some SEM images (these are not seen in figure 3 as this is a cross-sectional view). Figure 4 shows a pair of images where gold nano-pillars are clearly seen. These pillars were formed on the (111) planes and between the domains during the infiltration and drying process of the Au solution when excess nano-gold colloid came out of the voids and dried up at the same time. These structures were typically 1 micron long and had a base diameter of about $100 \mathrm{~nm}$ and body diameter of $35 \mathrm{~nm}$.

3. Optical properties of gold-infiltrated synthetic opal films 
In order to observe changes in the optical properties of infiltrated opal films, reflection measurements were done, both before and after the infiltration of nanogold colloids. The sample was mounted on a rotating stage and was illuminated with a spot size of $1 \mathrm{~mm}^{2}$, using monochromatic light from a grating-equipped monochromator. The reflected light was detected by using a silicon detector followed by a lock-in amplifier. The reflectance measurements were made at various angles of incidence. The upper panel in Figure 5 shows normalised reflectance measurements, before and after infiltration, at $15^{\circ}$ angle of incidence. A red shift in the reflectance measurements was observed due to the change in the value of $n_{\text {eff. }}$ By altering the angle of incidence $(\theta)$, the effective refractive index $\left(n_{e f f}\right)$ and the inter planar spacing $(d)$ can be determined by the following equation $[15]$.

$\lambda=2 d\left(n_{\text {neff }}^{2}-\sin ^{2} \theta\right)^{1 / 2}$

Using the plot shown in the lower panel of Figure $5, n_{\text {eff }}$ can be measured and it was found to have increased from 1.46 to 1.66 , due to the infiltration of gold nano-particles. Figure 6 shows the normalised reflectance measurements obtained at various angles of incidence from the $\mathrm{Au}$ infiltrated opal films. The lattice diffraction peaks were shifted towards shorter wavelengths by increasing the angle of incidence, which is in accordance with the modified Bragg's law. From this figure it is also obvious that some features appeared at a constant longer wavelength with each successive increase in angle measurement. In the present case metal (i.e. Au) was infilled in the voids of opal. Visible light (radiation in the 
$400 \mathrm{~nm}$ to $700 \mathrm{~nm}$ wavelength range) cannot get inside a metal, or at least it cannot penetrate very far. It is possible for light to be trapped at the surface of a metal and propagate around in a state known as surface plasmon, therefore this behaviour is attributed to surface plasmon resonance (SPR) effects $[15,16]$. The angle-resolved measurements at $15^{\circ}$ and $45^{\circ}$ show a single band around the same wavelength value of $770 \mathrm{~nm}$, whereas, at $60^{\circ}$, two bands appeared - at $650 \mathrm{~nm}$ and $770 \mathrm{~nm}$, as shown in figure 6. By increasing the angle of incidence, the intensity of the SPR was changed. However no significant shift of the band centred on 770 nm was produced by increasing the angle of incidence.

M. Quinten [17] has studied reflectance from both single and aggregated Au nano-particles. He found, both theoretically and experimentally, that the SPR of the single nano-particles appeared at shorter wavelengths, whereas SPR of the aggregated nano-particles appeared at longer wavelength.

In order to confirm the presence of the SPR bands, the lattice constant of the thin film was changed. Two more samples with different sphere sizes were fabricated by using the same technique as described earlier. $5 \mathrm{~nm}$ diameter gold nano-particles were infiltrated into the thin films. The optical reflectance properties were measured at $15^{\circ}$ angle of incidence. In the upper panel of Figure 7 (red line spectrum) the middle peak $(695 \mathrm{~nm})$ is the stop-band of the composite 3D $\mathrm{PhC}$. The band at longer wavelengths $(770 \mathrm{~nm})$ is the reflectance from the aggregated gold nano-particles, whereas the shorter wavelength band at $\sim 650 \mathrm{~nm}$ is the SPR of single $5 \mathrm{~nm}$ gold nano-particles. Similarly, in the lower panel of Figure 7 (red line spectrum) the first peak in the spectrum is the stop-band of the 
composite 3D PhC, whereas the second and third peaks represent the SPR of the 5 $\mathrm{nm}$ diameter gold nano-particles and reflectance from the aggregated gold nanoparticles, respectively.

\section{Conclusions}

A simple and easy method for the infiltration of $5 \mathrm{~nm} \mathrm{Au} \mathrm{nano-particles} \mathrm{into} \mathrm{the}$ voids of synthetic opal is reported. The infiltration was carried out by slow evaporation of a gold solution into the voids of the opal. The most common technique mentioned in the literature is the use of electrochemical deposition to infiltrate metals into the voids of the opal. The capillary-force infiltration technique has the advantage over the electrochemical deposition approach that thick opal films, i.e. ones more than 120 layers thick, can be infiltrated. The colour of the thin film changed after infiltration due to the increase in the effective refractive index of the opal from 1.46 to 1.66 . This approach gives a red shift in the stop-band of the synthetic opal. Optical reflectance measurements were made at various angles of incidence. Due to the metal (i.e. Au) infiltration, resonances were also found at longer wavelengths due to SPR effects. The same features were also observed by S.G. Romanov [16]. The SPR occurred at $770 \mathrm{~nm}$ when measured at angles of incidence of $15^{\circ}$ and $45^{\circ}$. At a still higher angle of incidence, i.e. $60^{\circ}$, an additional band appeared at $650 \mathrm{~nm}$. In contrast, no change in the position of the band attributable to SPR was observed by changing the angle of incidence. 


\section{References}

[1] M. Notomi, Optical and Quantum Electronics 34 (2002) 133-143.

[2] A. L. Pokrovsky and A. L. Efros, Phys. Rev. Lett. 89 (2002) 093901-093904.

[3] C. R. Simovski and S. He, Microw. Opt. Techn. Lett. 31 (2001) 214-221.

[4] S. Gupta, G. Tuttle, M. Sigalas and K. M. Ho, Appl. Phys. Lett. 71 (1997) 2412-2414.

[5] A. V. Blaaderen, Science 282 (1998) 887-888.

[6] A. R. Goodall, M. C. Wilkinson and J. Hearn, J. Polym. Sci. 15 (1977) 21932218.

[7] W. Stober, A. Fink, and E. Bohn, J. Colloid Interface Sci. 26 (1968) 62-69.

[8] W. Y. Zhang, X. Y. Lei, Z. L. Wang, D. G. Zheng, W. Y. Tam, C. T. Chan, and P. Sheng, Phys. Rev. Lett. 84 (2000) 2853-2856.

[9] A. Moroz, Phys. Rev. Lett. 83 (1999) 5274-5277.

[10] I. E. Kady, M. M. Sigalas, R. Biswas, K. M. Ho, and C. M. Soukoulis, Phys. Rev. B 62 (2000) 15299-15302. 
[11] P. N. Bartlett, J. J. Baumberg, P. R. Birkin, M. A. Ghanem, M. C. Netti, Chem. Mater. 14 (2002) 2199-2208.

[12] W. Li, G. Sun, F. Tang, W. Y. Tam, J. Li, C. T. Chan and P. Sheng, J. Phys.: Condens. Matter 17 (2005) 2177-2190.

[13] M. A. McLachlan, C. C. A. Barron, N. P. Johnson, R. M. De La Rue, D. W. McComb, J. Cryst. Growth 310 (2008) 2644-2646.

[14] M. A. McLachlan, N. P. Johnson, R. M. De la Rue and D. W. McComb, J. Mater. Chem. 14 (2004) 144-150.

[15] N. P. Johnson, D. W. McComb, A. Richel, B. M. Treble and R. M. De la Rue, Synth. Met. 116 (2001) 269-473.

[16] S. G. Romanov, A. S. Susha, C. M. Sotomayor-Torres, Z. Liang and F. Caruso, J. Appl. Phys. 97 (2005) 0861031-0861033.

[17] M. Quinten, Appl. Phys. B 73 (2001) 245-255. 
Figure captions

Figure 1. Optical micrograph before and after infiltration of $5 \mathrm{~nm}$ gold colloids in voids of the opal. The colour of the thin film changed due to increase in the effective refractive index.

Figure 2. SEM image of synthetic opal made from $230 \mathrm{~nm}$ diameter polystyrene spheres before (upper panel) and after (lower panel) infiltration of gold nanoparticles.

Figure 3. (Upper panel) SEM image of the (111) plane of synthetic opal made of $230 \mathrm{~nm}$ diameter polystyrene spheres, after infiltration of $5 \mathrm{~nm}$ diameter gold nano-particles. (Lower panel) SEM image of a cross-section of the synthetic opal made of $230 \mathrm{~nm}$ diameter polystyrene spheres, after infiltration of $5 \mathrm{~nm}$ diameter gold nano-particles.

Figure 4. (Upper panel) SEM image of thin film polystyrene opal after infiltration of gold nano-particles. Gold nano-pillars projecting from the edge of a cleaved domain are clearly seen. (Lower panel) SEM image of thin film after infiltration of gold nano-particles.

Figure 5. (Upper panel) Normalised Reflectance measurements before and after infiltration of gold nano-particles. (Lower panel) Plot of square of reflectance maxima versus $\sin ^{2} \theta$. After infiltration of gold nano-particles, the effective refractive index contrast increased from 1.46 to 1.66 . 
Figure 6. Reflectance measurements at various angles of incidence. Peaks from the lattice diffraction moved to shorter wavelength as discussed in the text.

Figure 7. (Upper panel) Reflectance measurement of thin film made of $270 \mathrm{~nm}$ diameter polystyrene spheres. (Lower panel) Reflectance measurements of thin film made of $216 \mathrm{~nm}$ diameter polystyrene spheres. 


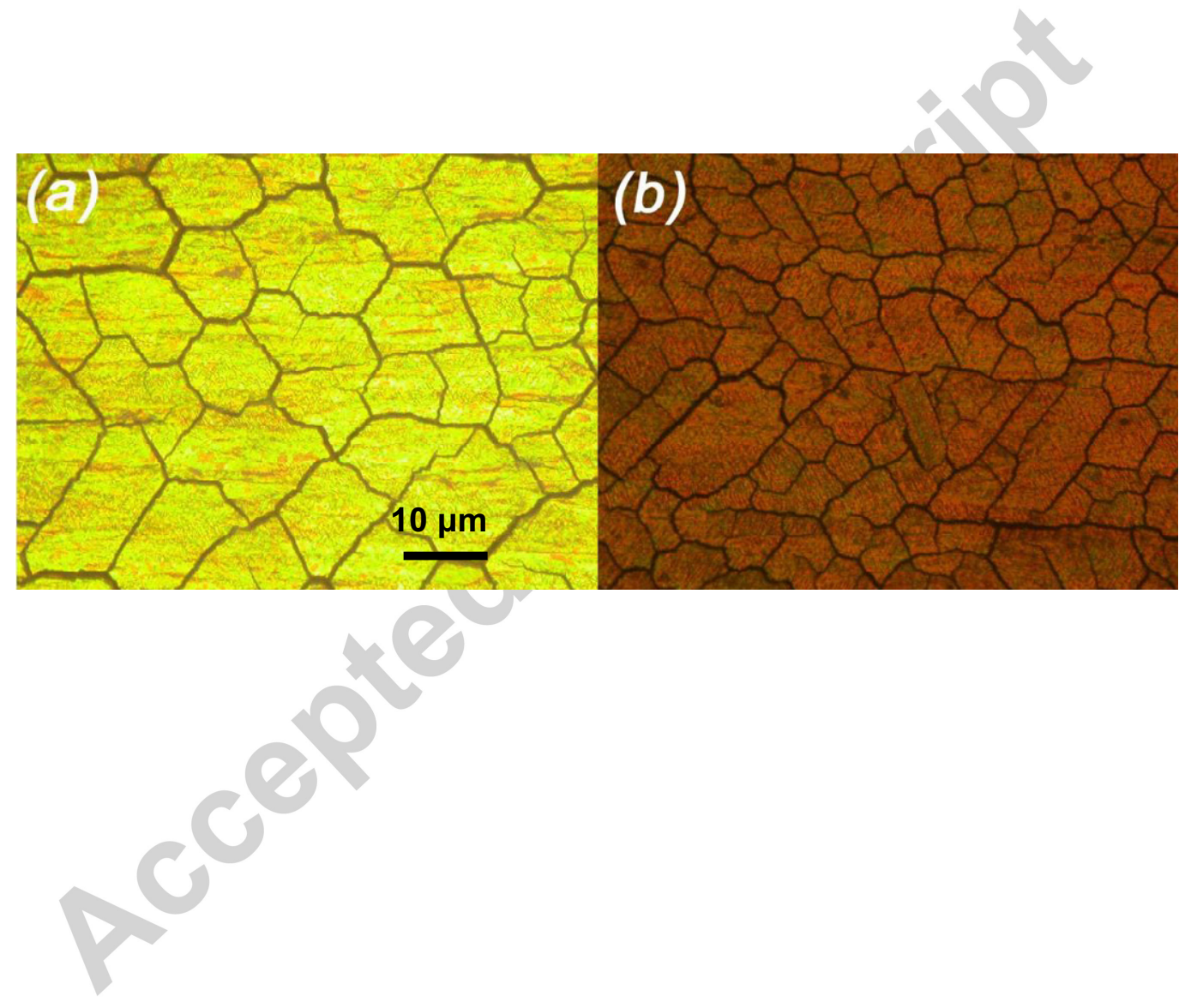


Figure 2
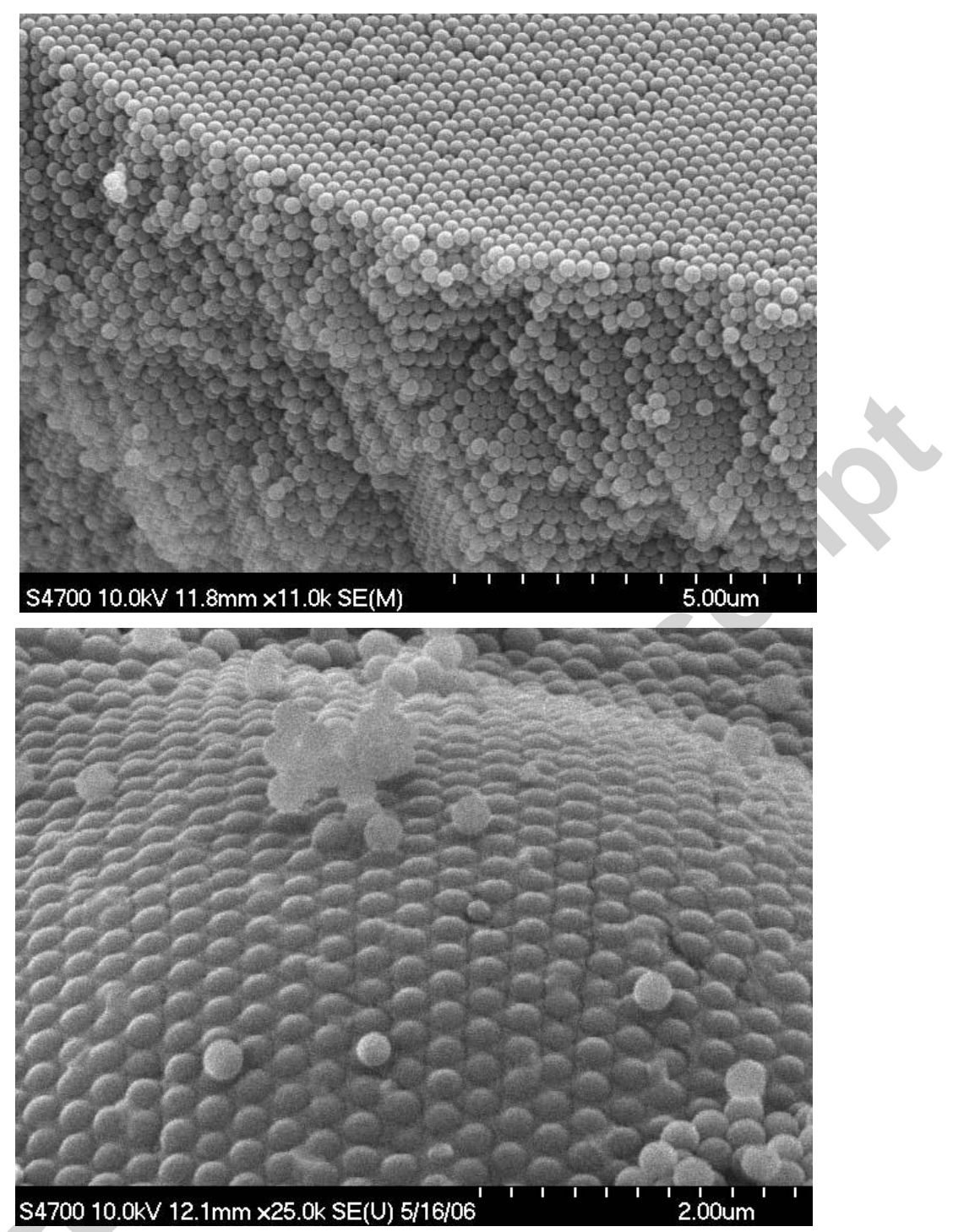
Figure 3

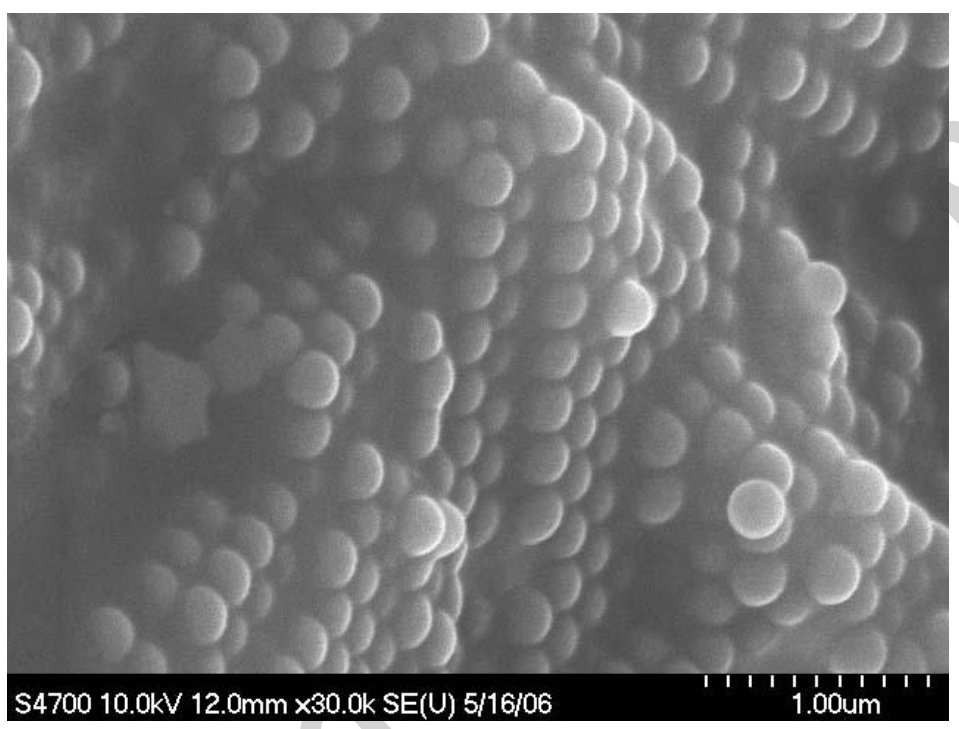




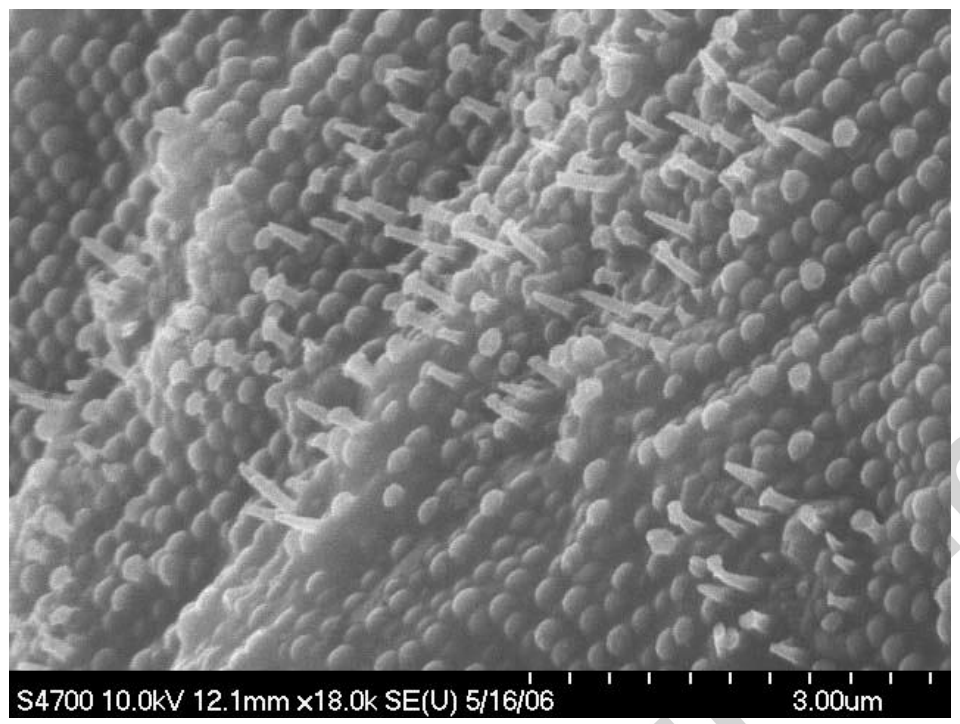

S4700 10.0kV $12.1 \mathrm{~mm} \times 18.0 \mathrm{k}$ SE(U) 5/16/06

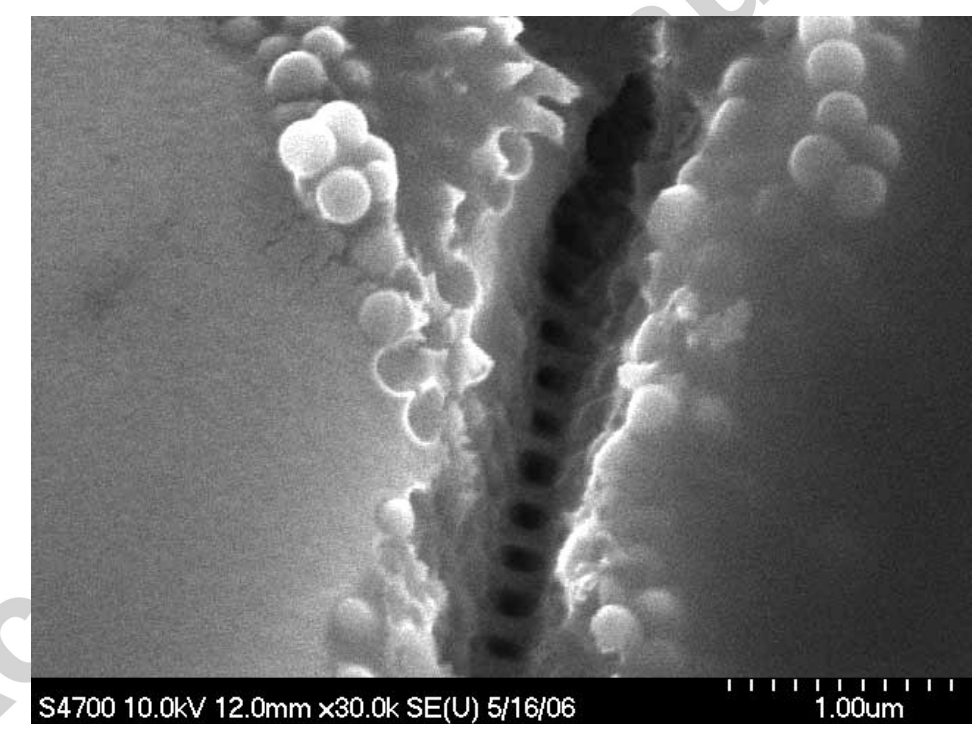



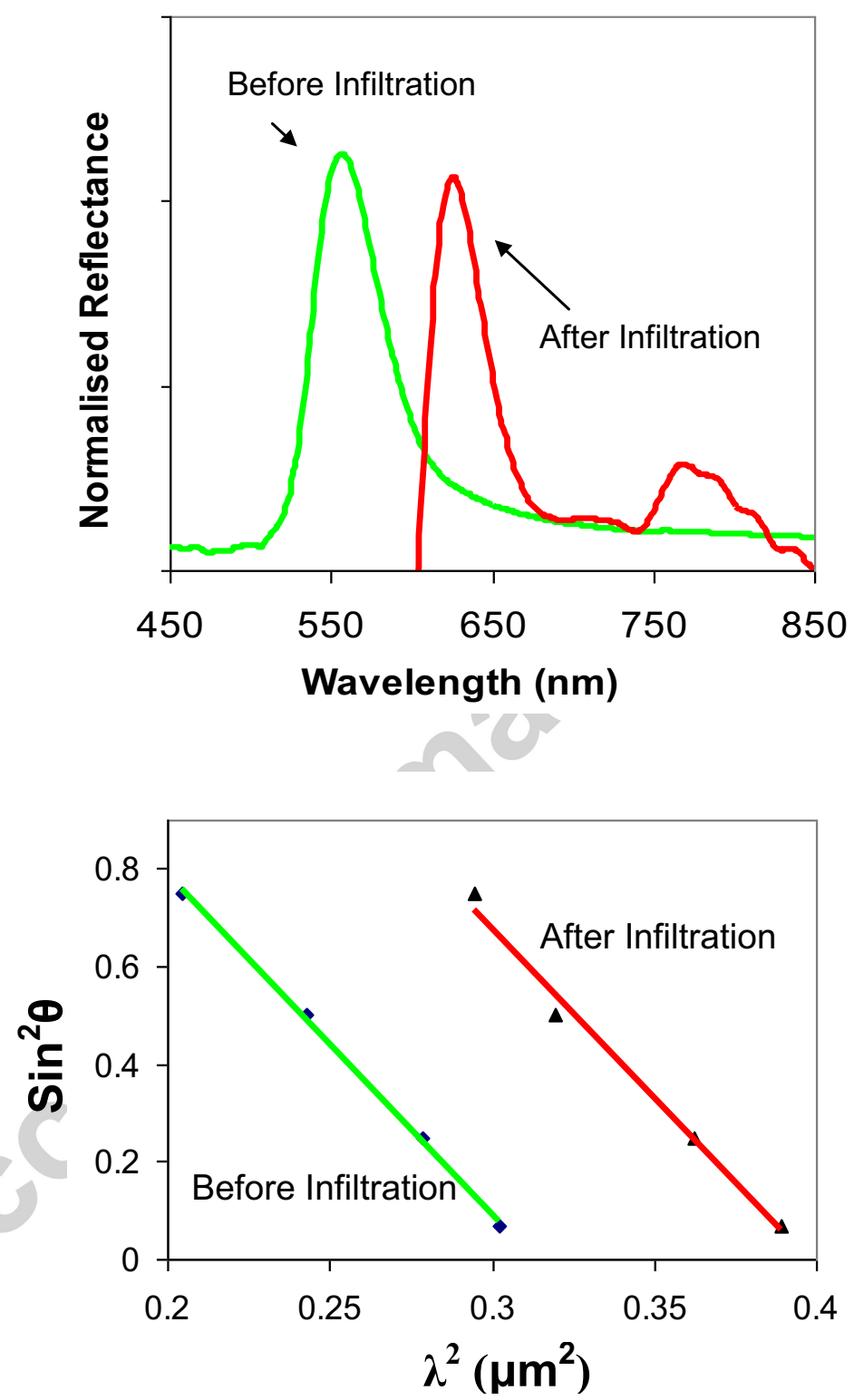
Figure 6

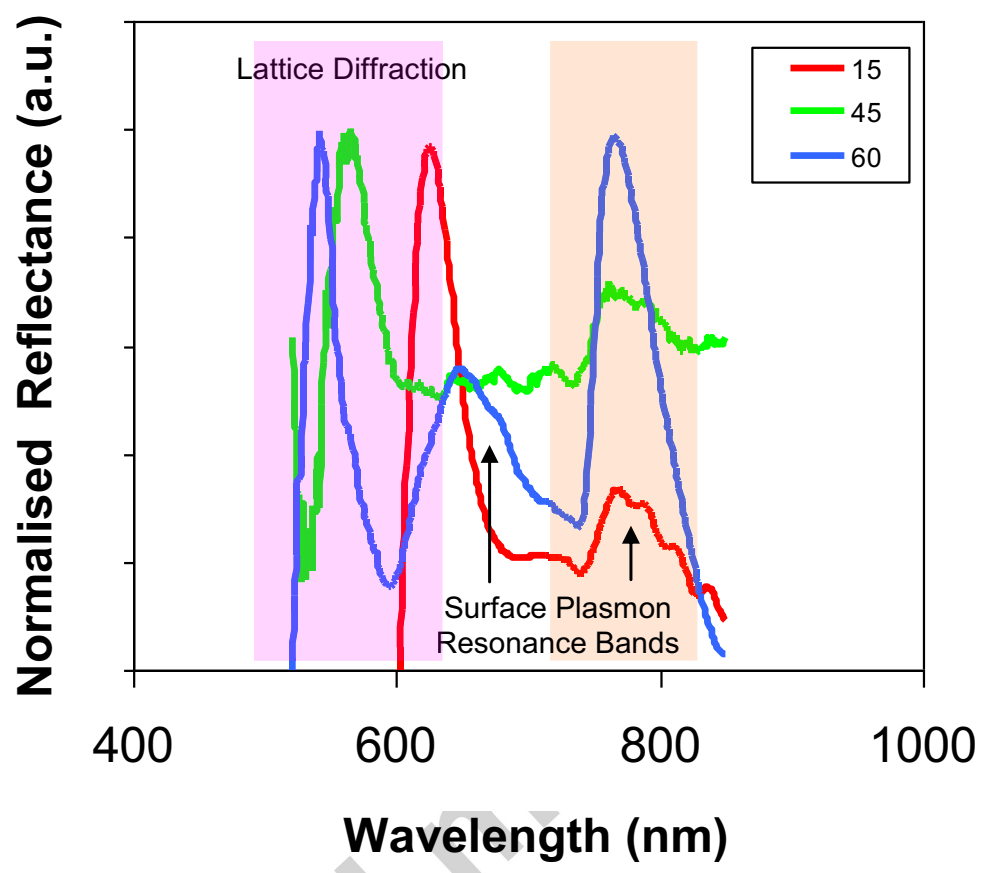


Figure 7

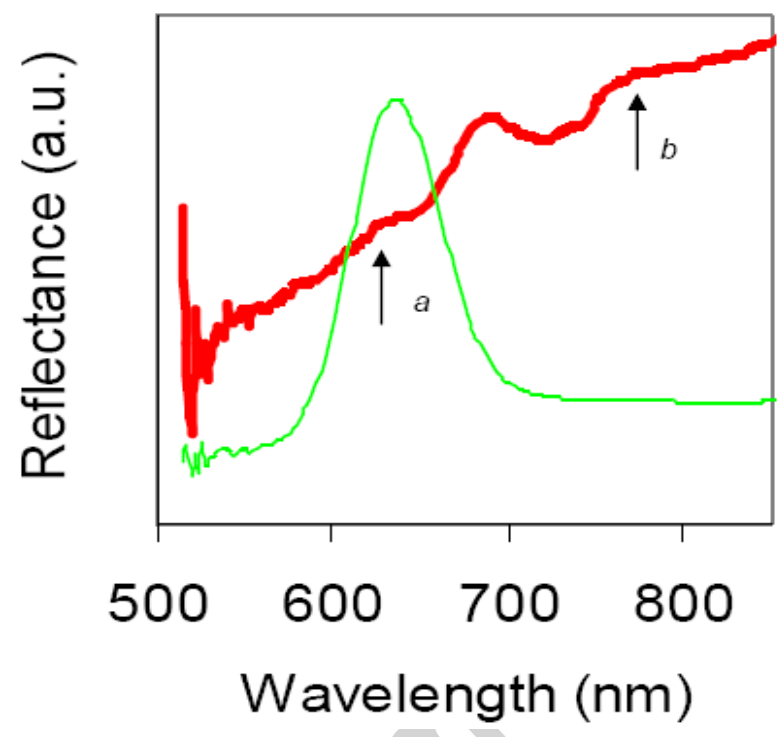




\section{Research Highlights}

In this work we show how to prepare polystyrene-based photonic crystals

We also show how nano-gold colloid can be infiltrated inside photonic crystals

We then demonstrate the optical properties of gold-infiltrated photonic crystals 